\title{
Heterogeneous Impact of Geographic Barriers on Provider Choice Evidence from New York County's Health Market*
}

\author{
Jae Bok Lee**, Chul-Young Roh***, and Jonathan A Woolley****
}

\begin{abstract}
Health services should be accessible regardless of citizens' gender, age, race, or insurance type, and geographic barriers should not interfere with this access. This article aims to assess the heterogeneous impacts of geographic barriers on inpatients' hospital choices and to examine whether they vary according inpatients' socioeconomic or insurance status. Using data on providers and inpatients obtained from the New York State Bureau of Health Informatics Office of Quality and Patient Safety for New York County (New York City's borough of Manhattan) for 2009, we employed a discrete choice model. Our findings reveal that geographic barriers limit inpatients' choices of hospitals more when they are of low socioeconomic status.
\end{abstract}

Keywords: hospital choice, geographic accessibility, access barrier, socioeconomic disparities

* This work was supported by the Ministry of Education of the Republic of Korea and the National Research Foundation of Korea (NRF-2015S1A5A2A03049823).

** Jae Bok Lee, corresponding author, is a visiting research fellow at the Korea Institute of Public Administration. E-mail: jaebok@kipa.re.kr.

*** Chul-Young Roh is an associate professor in the Health Services Administration Program, Department of Health Sciences, at Lehman College/ City University of New York. E-mail: chulyoung.roh@lehman.cuny.edu.

**** Jonathan A Woolley is a PhD candidate in the School of Public Affairs and Administration at Rutgers University-Newark. E-mail: jwoolley@scarletmail.rutgers. edu.

Manuscript received September 13, 2018; out for review September 23, 2018; review completed December 14, 2018; accepted December 17, 2018.

The Korean Journal of Policy Studies, Vol. 33, No. 3 (2018), pp. 23-45.

(C) 2018 by the GSPA, Seoul National University 


\section{INTRODUCTION}

Geographic accessibility to hospitals is not often considered a major issue for urban populations. This is probably because, unlike in a rural or exurban setting, most urban residents generally have at least one, and often more than one, hospital within a few miles' radius of where they live. Furthermore, urban hospitals often accept patients requiring inpatient services covered by Medicaid and Medicare (the government insurance programs for low income and elderly persons, respectively) as well as those covered by other insurance plans - and sometimes those not covered by any plan at all - meaning residents of various income and insurance coverage levels can generally find a hospital willing to handle their care within a reasonable distance of where they live. As a result, geographic accessibility-and the resultant issue of whether patients bypass a nearer hospital in favor of one further away - has received more emphasis in examinations of the subject from a rural, rather than an urban, perspective (Guagliardo, Ronzio, Cheung, Chacko, \& Joseph, 2004; Guagliardo, 2004).

Yet the issue of urban residents' geographic accessibility to hospital care is not without importance. A substantial portion of the U.S. population- $62.7 \%$-are urban dwellers (U.S. Census Bureau, 2015), and a higher proportion of that number are of lower socioeconomic status (Brown et al., 2004; Hall \& Owings, 2015). Urban residents may be more dependent on public transportation due to their financial means, which may alter their ability to access hospitals (Peipins et al., 2011; Gesler \& Meade, 1988). Their ability to pay insurance copayments, deductibles, or other payments required for hospital services may also vary, meaning that some may be able to afford hospital services that others may not (Akinyemiju Sakhuja, \& Vin Raviv, 2016; Gusmano, Burke, \& Thompson, 2012; Park, 2011). Urban areas often contain both locally prestigious academic medical institutions and relatively unremarkable community hospitals, and some urban doctors may prefer to affiliate with a more prestigious hospital that is further away from where their patients live, regardless of their patients' ability to access that facility, rather than with a less prestigious one closer to their patients' homes. In addition, within a city there may be great variations in hospital density: some neighborhoods, such as downtowns or university districts, may be well served by medical facilities, while other neighborhoods, such as low-income ones, may be comparative hospital deserts. Regarding urban health care provision in general, Luo and Wang (2003, p. 865) write, "Access to health care varies across space because access to health care is affected by where health professionals locate and where people reside, and neither health professionals nor population is uniformly distributed." 
Previous researchers found that patients tend to bypass rural hospitals in order to receive better care elsewhere (He, 2011; Varkevisser \& van der Geest, 2007). When it comes to public health services, however, the findings are inconsistent. Some articles find patients who use public insurance such as Medicaid are less likely to bypass hospitals that are closer to them (Roh \& Lee, 2005). This may suggest that distance limits patients' choice of providers when they seek to take advantage of public health benefits. Patients with resources appear to choose to travel longer distances when in need of riskier services, and women from counties with large Medicaid populations also more frequently bypass nearby hospitals (Bronstein \& Morrisey, 1991).

However, the effect that geographic barriers has on disparities in health care service cannot be readily monitored. To address this problem, this article builds on the findings from rural areas and investigates whether the hospital choices of inpatients of low economic status in urban areas are restricted by distance factors. First, it considers whether an individual's risk of having to make a nonoptimal decision (because the person's options are limited) increases when the distance costs rise (distance costs here refer to the costs incurred by travel to or from the hospital). Second, it considers whether an individual's risk of having to make a nonoptimal decision (i.e., having to give up choices) is much higher for inpatients of low socioeconomic status than for those of higher socioeconomic status. This is because the heterogeneous impact of geographic barriers, which we analyze here, may prevent these patients from exercising their planned choices. We use data documenting all inpatients and providers in New York County (New York City's borough of Manhattan) for 2009, which we obtained through the New York State Bureau of Health Informatics' Office of Quality and Patient Safety (SPARCS). ${ }^{1}$

Our findings show that inpatients of low socioeconomic status choose hospitals farther away from them less often than others and that a low socioeconomic status strengthens the negative effect of distance barriers and thus can affect these patients' decision-making process. These inpatients are less able to choose excellent providers and often must instead opt for the closest ones. These findings may be of considerable interest to local health care administrators and policy makers, as

1. SPARCS is a comprehensive all-payer data reporting system established by a joint effort between the health care industry and government in 1979 (www.health.ny.gov/statistics/ sparcs). The system was initially created to collect information on discharges from hospitals. SPARCS currently collects information on inpatient characteristics, diagnoses and treatments, services, and charges for each inpatient stay and for ambulatory surgery, emergency department, and outpatient services, including visits to diagnostic or treatment centers licensed to provide ambulatory surgery services. 
well as possibly to those at a higher level of government, as they suggest that public officials need to find ways to give these patients more hospital choices.

\section{LITERATURE}

In theory, in competitive markets, each patient has enough bargaining power to play hospitals off each other. Using this bargaining power, they can extract a higher quality of services from the hospital they choose to go to. However, in reality, the market mechanism does not guarantee rational decision-making ability for everybody. There are impediments to choosing an appropriate hospital, which are associated with socioeconomic status and are affected by many access barriers. Access barriers to health services are generally defined in terms of four characteristics: geography, availability, affordability, and acceptability (Jacobs, Ir, Bigdeli, Annear, $\&$ van Damme, 2011). Here we focus on geography and the ability a patient needing inpatient services to access each hospital in the market where the patient resides.

The question of what constitutes an optimal versus a nonoptimal decision is, of course, central to any discussion of rational decision making. However, although the question is often raised in the literature of both public administration generally and health administration specifically, the terms "optimal" and "nonoptimal" rarely are explicitly defined. We define an optimal decision as one that allows the inpatient to make the best possible rational decision, unfettered by constraints imposed by a lack of resources. A nonoptimal decision is, therefore, one that is not the best possible decision. This follows the prevailing literature: Gössling (2003, p. 126) views a nonoptimal decision as one not providing the most advantageous result, Celikel, Hustache, De Lepinay, Martin, and Melrose (2005, p. 1) observe how difficulties in defining the available options can interfere with reaching an optimal decision, and Amit and Schoemaker note the "pervasive uncertainty and complexity faced by managers, often resulting in suboptimal Strategic Assets decisions" (1993, p. 44). (It should also be noted $\mathrm{Lu}$ et al. define regret as "as the opportunity loss to the decision maker" if a nonoptimal decision is taken [2005, p. 4].) For the purposes of this study (which concerns socioeconomic status), we specifically concentrate on the financial resources allowing one to travel to the hospital of one's choice when considering whether or not one can make an optimal decision.

Over the years, there have been a number of studies concerning bypassing behavior as a pattern of seeking health care outside the local community (Liu, 2016). Many researchers have found evidence of bypass behavior in rural locations 
such as Alabama (Bronstein \& Morrisey, 1991) and Kentucky (Ona, Allen, Davis, \& He, 2016; He, 2011) in the United States and other countries such as Italy (Brau, Moro, \& Balia, 2016) and Britain (Haynes, Lovett, \& Sünnenberg, 2003). Most studies on geographical access have concerned the bypassing behavior of patients in rural locations rather than in densely populated urban environments. Key resources such as knowledge, money, power, prestige, and beneficial social connections can be used no matter what the risk and protective factors are in a given circumstance.

In this context, therefore, there is scope for the applicability of these studies to New York City. Regarding research on large cities, the findings of Morrill, Earickson, and Rees (1970) show that patients may be likely to choose a hospital at a distance from their places of residence. Some articles examine spatial accessibility to health care at a local level in the Chicago region (Luo \& Wang, 2003; Yang, George, \& Mullner, 2006), but few studies examine individual choice behaviors.

This article grapples with the question of the link between geographical barriers to access and socioeconomic resources, such as gender, age, race and insurance types (public or private) and examines whether access barriers impede efforts of inpatients of low socioeconomic status to exercise a choice when it comes to which hospital to go to compared to others. It stands to reason that the failure to take the impact of these inpatients' higher distance costs into account would lead to public health inequalities.

New York City's Department of Health and Mental Hygiene documents both the types of health insurance utilized by city residents and how much the insurance costs and the number of uninsured city residents, as well as the number of city residents who seek medical care, particularly primary care (New York City Department of Health and Mental Hygiene, 2007, 2010, 2014; Raufman, Farley, Olson, \& Kerker, 2007). McLafferty and Grady (2005) find that the geographic access of immigrant groups in Brooklyn to prenatal care is more limited than that of American-born women; however, Medicaid recipients among both American-born and foreign-born women patronized a larger range of prenatal clinics than nonrecipients. This suggests that foreign-born women are more choosy about which provider they use when they receive public insurance. Similarly, Nguyen, Waddell, Thomas, Huston, Kerker, \& Gwynn (2011) investigate hypertension and hypercholesterolemia in the city and find that what primarily determines whether a person is aware that he or she has either of these conditions and obtains treatment for them are having a routine place of care and his or her insurance status. These findings seem to throw doubt on the idea that individuals are able to make optimal choices. Distance impedes patients' ability to access health services, and their socioeconomic status 
affects their choices as to which provider to go to. This article posits that individuals' risk of having to make a nonoptimal decision increases when the distance costs to choose a different provider go up and that the risk of making a nonoptimal decision is much higher among inpatients of low socioeconomic status or who have public insurance than among other groups.

There are reasons for conducting a separate study exploring how geographic barriers impact New York City resident's hospital choices. First, the studies by Luo and Wang (2003) and by Yang, Goerge, and Mullner (2006) concentrate on methodological issues; patient behavior is secondary. Second, they (along with McLafferty \& Grady, 2005, Nguyen et al., 2011, and the Department of Health and Mental Hygiene) concentrate on health care services that typically are not provided in a hospital setting, meaning the people using them may not follow the same choice patterns as with hospital visits. Third, Morrill, Earickson, and Rees (1970) use data from 1965, and thus it is likely outdated. Furthermore, it uses only general designations for patients' residential locations (although it is clearly based on a data source that was more specific), and so the accessibility and bypassing issues experienced by patients within each designation could vary widely. Last, the emphasis on other studies has typically been on the effect of low socioeconomic status at the statewide rather than the city level (Giacovelli et al., 2008, O’Brien-Irr, Harris, Dosluoglu, \& Dryjski, 2012). While it is undeniable that New York City's results play a key role in these findings regarding the state as a whole, results from other parts of the State (such as rural areas) may counterbalance those of New York City.

Regarding findings from rural areas, Bronstein and Morrisey (1991), for instance, find that wealthier and Medicaid-covered expectant mothers in rural Alabama are more likely to bypass their nearest rural hospital in favor of receiving obstetric services at metropolitan or other hospitals, with wealthier ones more likely to travel to metropolitan hospitals (presumably because of perceived better levels of care). Tai, Porell, and Adams (2004) likewise find that wealthier Medicare beneficiaries and those who are used to traveling longer distances for office visits with their physician are more likely to bypass their local rural hospitals in favor of others, particularly if the chosen hospital is thought to provide better care, but that overall Medicare patients preferred to be hospitalized close to home. Brau, Moro, and Balia (2016, p. 17), writing in an Italian context, find that "the most effective pull factors are the number of beds, doctor intensity and low distance" but also propose that after patients secure a medical consultation outside the area they reside in, they opt to receive "expensive treatment in hospitals near home." Thus, they provide a possible reason for why people choose to use local hospitals over perhaps better but more distant facilities. 
Other studies have also looked at the reasons rural residents choose one hospital over another, focusing on why these residents choose further away hospitals over local ones. Liu, Bellamy, Barnet, \& Weng (2008), for instance, find the density of primary care physicians, the quality and services available at the local hospital, and demographic factors all factor into a rural resident's decision to bypass a local hospital for one farther away. Ona et al. (2016), building on the work of He (2011), find that numerous rural Kentuckians bypass their local hospitals in favor of metropolitan ones, the reasons being the perception that the quality of the care and services available at the metropolitan hospital surpass those of the local hospital, along with socioeconomic factors and the payment methods accepted at the hospitals.

Focusing more specifically on distance and geographic issues, Haynes, Lovett, and Sünnenberg (2003) find a that both rural residents and residents of small urban areas in Britain were more likely to bypass the nearest primary doctor for one slightly further away. Moscone, Tosetti, and Vittadini (2012), using data on all patients admitted to hospitals in Lombardy, show that geographical factors, such as the distance from a hospital, are important considerations for patients making decisions about which hospital to go to. Studies of patient-hospital choice determinants in the United States have shown similar results. For example, using Medicare data on all patients hospitalized in California and a sample of other bordering hospitals, Pope (2009) finds that hospital rankings and geographic proximity affect patient choice. Luft et al. (1990), focusing on patient choice in three geographic areas in California for the year 1983 and using a conditional logit model to analyze the influence of quality, ownership, and distance in patient hospital choice, suggest that patient flows are positively associated with high hospital quality and find that teaching hospitals are more likely to be chosen by patients.

What literature there is on the relationship between distance and choice of which provider to go to in a sizable urban environment is largely concerned with the use of providers of specific types of services - some of which may not be available in a hospital - rather than of hospitals themselves. Furthermore, with the notable exception of Luo and Wang's (2003) and Yang et al.'s (2006) articles that focus on Chicago, studies have often concentrated on cities that are either substantially smaller than New York, Los Angeles, Chicago, and San Francisco, such as Savannah, Georgia, and cities in Tennessee (Gesler \& Meade, 1988; Rocha \& Kabalka, 1999), or have investigated the question using cities that are physically as big as New York, Los Angeles, Chicago, and San Francisco but that have a notably lower population density, such as Atlanta (Peipins et al., 2011). Keating et al. (2016) is an exception, but their study concerns female senior citizens - results for other segments of the population, particularly those of working age, may be quite different. 


\section{METHOD}

\section{Data}

This article explores whether geographic issues exacerbate socioeconomic disparities for patients choosing hospital providers. We use data for all inpatients and providers in New York County for the year 2009. We chose 2009 because it was the year before the Affordable Care Act was passed, because no person was yet mandated to purchase health insurance and the number of Medicaid-eligible persons had not yet been expanded due to the act's passage. Thus, not only were inpatients still using a medical billing and payment system they were likely familiar with but inpatients of low socioeconomic status had not yet secured the insurance that the Affordable Care Act made possible that would make both hospital and nonhospital care more affordable. Our data were obtained from the SPARCS database of the New York State Bureau of Health Informatics' Office of Quality and Patient Safety.

\section{Dependent Variable}

For the purposes of this study, we first defined the market as all of the hospitals of New York County. We reached this definition by calculating the hospital choices inpatients made as a percentage of the total choices made in each county of New York City for the period $\left(-u_{i j}=U\left(C_{i j}, H_{i j}\right)\right.$. Our data for New York County suggests that $97 \%$ of inpatients chose their own county's hospitals. The findings reveal that most of the demand of inpatients was met by the supply of hospitals located in the same county; in this regard, the most suitable location for further analysis is New York County. This is in line with McLafferty and Grady's (2005) study, which assumes New York City's borough of Brooklyn to be one geographic market in its empirical analysis of health markets. To analyze which hospital a person chooses within a geographic market (called a "choice set" in the model), this article specifies identifier variables for matched groups (an inpatient and his or her hospital).

Identifier variables, as dependent variables, equal to one indicate a positive outcome (chosen), whereas those equal to zero indicate a negative outcome (not chosen). A patient's (geographic) market means a geographic choice set that contains multiple hospitals that he or she is able to access. Here, the choice set of hospitals consists of fifteen hospitals located in New York County during the period analyzed.

Our definition of choosing a hospitals is slightly different from the definition of bypassing a hospitals. The definition of bypassing is when a patient chooses a hos- 
pital that is outside the postal code of his or her residence. This is used by Fong et al (2016), Ona et al. (2016), Liu et al. (2008), and numerous other researchers and is similar to that used by Gesler and Meade (1988) and Morrill, Earickson, and Rees (1970), among others. It allows for an easier analysis of the available data than other approaches, such as those that rely on census tracts, while at the same time providing enough neighborhood detail to allow one to draw demographic conclusions about people's hospital choices. In recent years, a couple of researchers have questioned the use of zip codes as the best measurement for location, including Bow et al. (2004), who say it works in many cases but not all, and Luo and Wang (2003) and Grubesic and Matisziw (2006), who note the risks of using zip codes for epidemiological studies of New York State. However, the large number of successful studies using zip codes (Radcliff, Brasure, Moscovice, \& Stensland [2003], for instance) leads us to believe the choices that inpatients make in the reveal geographic barriers that may be affecting their decisions.

\section{Independent Variables}

Our primary independent variable is the distance from each inpatient's home location (based on postal code) to the hospital he or she chose, which we measured using the Arc View program. To capture the impact of socioeconomic factors, we use independent variables representing gender, age, and race (our variable for race measures white, black, Asian and other). Furthermore, we employ a category for insurance types, including private insurance, Medicaid, Medicare, uninsured, and other. Table 1 shows the five variables we selected, which are in line with those posited by Roh and Lee (2005).

\section{Controls}

For capturing hospital conditions, we included 15 dummy variables. These serve to control for unobserved characteristics of hospitals. Among control variables, the severity of the medical condition, which is measured by the total length of stays and by whether surgical or medical care is needed from their diagnosis-related group codes, is a significant predictor, because severely ill inpatients would require a hospital with more resources and services. 
Table 1. Variables and Measures

\begin{tabular}{|c|c|c|c|}
\hline Variable & Category & Measure & Measure \\
\hline dependent & choice & $\begin{array}{l}\text { inpatient' } \\
\text { hospital } \\
\text { choice }\end{array}$ & $\begin{array}{l}1 \text { if a certain hospital in a choice set is chosen by an } \\
\text { inpatient } \\
0 \text {, if other hospitals unchosen by an inpatient (the } \\
\text { choice set consists of } 15 \text { hospitals) }\end{array}$ \\
\hline \multirow[b]{2}{*}{ independent } & distance & miles & $\begin{array}{l}\text { distance between the inpatients' residences and } \\
\text { hospital chosen }\end{array}$ \\
\hline & $\begin{array}{c}\text { public-private } \\
\text { Service }\end{array}$ & insurance & $\begin{array}{l}\text { 1, if uninsured; } 0 \text {, otherwise } \\
\text { 2, if Medicaid; 0, otherwise } \\
3 \text {, if Medicare; 0, otherwise } \\
\text { 4, if private insurance; } 0 \text {, otherwise } \\
5 \text {, if other (Blue Cross, worker's compensation, other } \\
\text { nonfederal/federal insurance); } 0 \text {, otherwise }\end{array}$ \\
\hline \multirow[b]{3}{*}{ inpatients } & \multirow[b]{3}{*}{$\begin{array}{c}\text { demographic } \\
\text { factors }\end{array}$} & gender & 1 , if female, 0 , otherwise \\
\hline & & age & Age \\
\hline & & Race & $\begin{array}{l}\text { white, } 1 \text {, if white; } 0 \text {, otherwise } \\
\text { black or African American; } 1 \text {, if black; } 0 \text {, otherwise } \\
\text { Asian, } 1 \text {, if Asian; } 0 \text {, otherwise } \\
\text { other, } 1 \text {, if others; } 0 \text {, otherwise }\end{array}$ \\
\hline \multirow[t]{2}{*}{ control } & \multirow{2}{*}{$\begin{array}{l}\text { medical } \\
\text { conditions }\end{array}$} & $\begin{array}{l}\text { surgical vs. } \\
\text { medical } \\
\text { condition }\end{array}$ & $\begin{array}{l}\text { 1, if the inpatient has a surgical DRG conditions; } 0 \text {, } \\
\text { otherwise }\end{array}$ \\
\hline & & $\begin{array}{l}\text { length of } \\
\text { stays }\end{array}$ & $\begin{array}{l}\text { indicates the duration when inpatient was } \\
\text { hospitalized }\end{array}$ \\
\hline
\end{tabular}

Table 2. Descriptive Statistics

\begin{tabular}{c|c|c|c|c}
\hline Variables & Mean & $\begin{array}{c}\text { Standard } \\
\text { Deviation }\end{array}$ & Minimum & Maximum \\
\hline Hospital Choices & 0.06 & 0.24 & 0 & 1 \\
\hline Distance (Miles) & 0.88 & 1.25 & 0 & 10 \\
\hline $\begin{array}{c}\text { Distance (Miles) } \\
\text { Squared }\end{array}$ & 2.34 & 5.91 & 0 & 104 \\
\hline Insurance Types & & 0.47 & 0 & 1 \\
\hline Private Insurance & 0.32 & 0.19 & 0 & 1 \\
\hline Uninsured & 0.04 & 0.30 & 0 & 1 \\
\hline Medicaid & 0.10 & & &
\end{tabular}




\begin{tabular}{c|c|c|c|c}
\hline Medicare & 0.48 & 0.50 & 0 & 1 \\
\hline Other & 0.06 & 0.24 & 0 & 1 \\
\hline Demographic Factors & & & & \\
\hline Gender (1=female) & 0.48 & 0.50 & 0.00 & 1.00 \\
\hline Age & 69.07 & 16.34 & 1 & 107.07 \\
\hline Race & 0.61 & 0.49 & 0.00 & 1.00 \\
\hline White & 0.38 & 0.49 & 0 & 1 \\
\hline Black & 0.32 & 0.47 & 0 & 1 \\
\hline Asian & 0.04 & 0.20 & 0 & 1 \\
\hline Other & 0.26 & 0.44 & 0 & 1 \\
\hline Controls & & 8.81 & 1.00 & 826.00 \\
\hline $\begin{array}{c}\text { Total Length of Stay } \\
\text { Medical Condition } \\
\text { (Surgical=1) }\end{array}$ & 0.31 & 0.46 & 0.00 & 1.00 \\
\hline Observation & & \multicolumn{5}{|c}{20,929} & \\
\hline
\end{tabular}

Note: The variable "other" in the race category includes Native American or Alaskan Native, Native Hawaiian or other Pacific islander, other races, and unknown. The variable "other" in the insurance category includes Blue Cross, Tricare, other nonfederal programs, disability, Title V, unknown (SPARC, 2014, pp. 54-82).

\section{Model}

A version of the demand for choice model was first proposed by McFadden (1974), and a variety of methodologies have been used with the choice model to analyzing health care provider choices including multinominal logit, multinominal probit (Canaviri, 2007), nested multinominal logit (Dor et al., 1987), mixed logit models (Borah, 2006), and conditional logit models (Roh, Lee, \& Fottler, 2008).

In order to investigate choices of inpatients by setting up an economic model framework, we use a discrete choice model. The model uses direct and indirect utility functions for those individuals who had to choose between providers. The benefit from receiving health care is important in life, and the cost of medical care means a reduction in the consumption of other goods. Moreover, the inpatient is assumed to choose the health care alternative that yields the maximum expected utility. Let the utility function be:

$$
\left(-u_{i j}=U\left(C_{i j}, H_{i j}\right)\right.
$$


There are individuals facing $j$ alternatives, where $j \in \mathrm{n}, \mathrm{n}\{1,2, \ldots, \mathrm{N}\} . u_{i j}$ is the direct conditional utility that individual $i$ expects from provider $j, C_{i j}$ is the individuals' level of consumption other than medical expenses, and $H_{i j}$ is expected level of improvement in health after receiving a treatment given an election of a provider. The usual assumptions about the utility function apply here: $U_{c}>0, U_{c c}<0$ and $U_{H H}<0$ (Canaviri, 2007). Both observed and unobserved characteristics of the individual seeking health care and the provider play a role in health care demand. The individual's observed characteristics can be gender, age, race, and income, and unobserved characteristics, represented by a dummy variable for each hospital, include an individual's perception of the level of quality and service of the provider, preference for certain medical procedures, or just a preference for being treated in certain way.

Our model specifies that the probability of hospital choice is an interaction of distance and inpatient attributes. A utility function of inpatient $i$ when he or she is choosing hospital $j$ is composed of $\left(C_{i j}, H_{i j}\right) . C_{i j}$ are measured by $\left(x_{i} d_{i j}\right)$ that are interaction of some individual characteristics such $\left(x_{i}\right)$ as age, gender, race, payment type, and severity of illness (medical condition or length of stay) with the provider attributes, $\left(d_{i j}\right)$ because inpatients' preferences with respect to hospital $j$ will vary. $H_{i j}$ is measured by $\left(d_{i j}\right)$ that is the preference of individual $i$ for an observed attribute of provider, which is the distance from an inpatient to a hospital $j\left(d_{i j}\right)$. Lastly, the individual's unobserved attributes are incorporated in an error term $\left(\varepsilon_{i j}\right)$ that accounts for possible additional unknown factors, and the consumer's valuation of a provider's unobserved attributes are measured by a dummy variable for each hospital $j\left(\delta_{j}\right)$. A dummy variable is necessary because we cannot observe all of the characteristics of hospitals (an outside alternative is a hospital located outside the market, which in our study means outside New York County).

Thus, using a liner function in which all the observed and unobserved attributes are specified and which represent idiosyncratic individual preferences, assumed to be independent of the hospital characteristics and of each other, we determine the inpatient's utility function as follows:

$$
u_{i j}=\alpha_{0} x_{i} d_{i j}-\alpha_{1} d_{i j}+\delta_{j}+\varepsilon_{i j}
$$

This model enables us to assess the probability that each inpatient goes to each hospital within the choice set of hospitals. We examine if their distance costs will be exacerbated if they have public insurance rather than private insurance or if their socioeconomic status is low rather than high. 


\section{FINDINGS}

Figures 1, 2, 3, and 4 show the distance distributions of inpatient choice of hospital depending on their socioeconomic status such as gender, age, race, and income status (reflected what type of insurance an individual has). These indicate that geographic accessibility to health care varies according to those factors.

The first figure shows that the distances from a hospital that black or Asian inpatients choose are dense at the point of zero (miles) from distance distributions. Thus, these inpatients appear to choose nearby hospitals within the same market more often than white inpatients. The second figure shows that older inpatients are denser at the point of zero to two (miles) compared to younger inpatients. The third figure shows female inpatients are slightly denser at the point of zero. All told, minorities such as black, Asian, elderly, or female inpatients are less likely to go to a hospital that is farther away from their place of residence than others who are younger, white, and male. This suggests that patients with fewer resources are more likely to choose nearby hospitals. This means that the distance of hospitals from inpatients of low socioeconomic might limit their options compared to others in the population. The greater the distance between the inpatient's residence and the hospital, the less likely are inpatients from low socioeconomic brackets to choose that hospital versus others. People may be better able to access other hospitals once they receive reimbursements, as such reimbursements can at least help reduce the burden of travel costs on top of medical costs.

Figure 4 shows that inpatients with public insurance or Medicaid or who are uninsured are denser at the point of zero, meaning that they are more likely to go a nearby hospital than those with private insurance. Medicaid or uninsured patients can be used as a proxy for patients of low-income status because these patients are generally unlikely to be earning an income allowing them to be able to afford private insurance (Bronstein and Morrisey, 1991; Tai et al., 2004). (Uninsured patients can often represent financially vulnerable patients given that they can be exposed to the risk of high hospital bills without any level of financial protection to offset those costs.) 
Figure 1. Distance from Patients to Hospitals Based on Gender

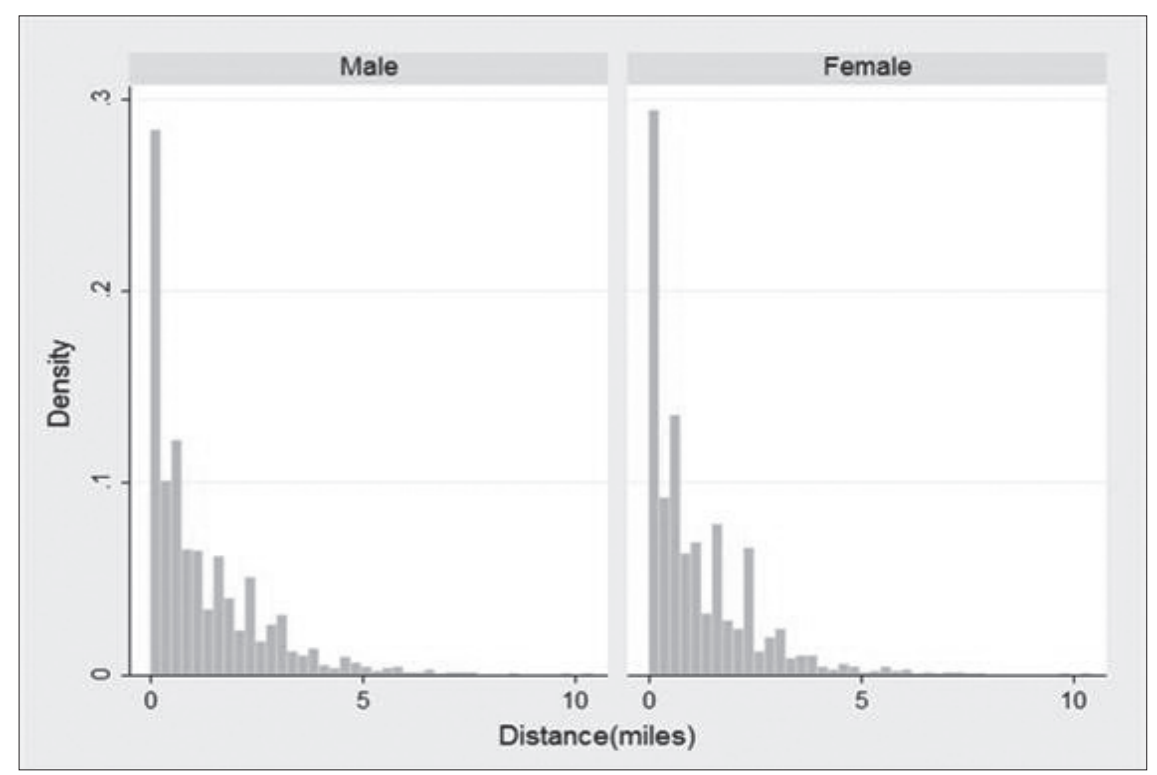

Figure 2. Distance from Patients to Hospitals Chosen Based on Age

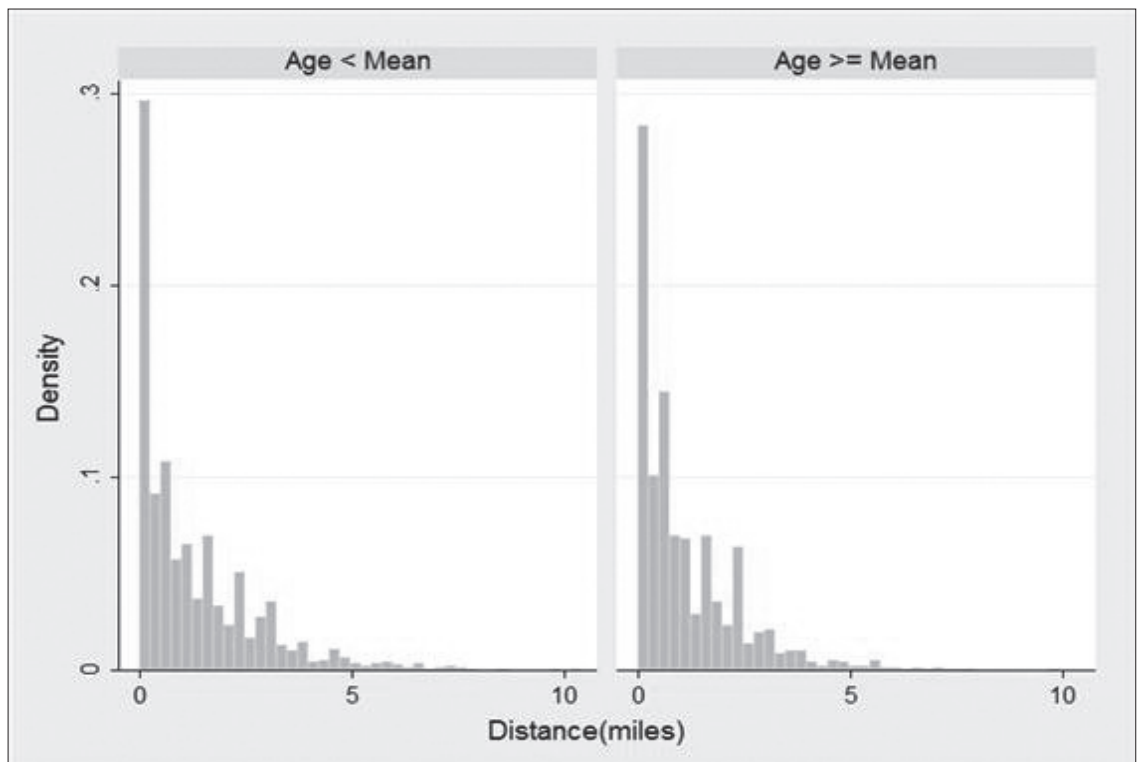


Figure 3. Distance from Patients to Hospitals Based on Race

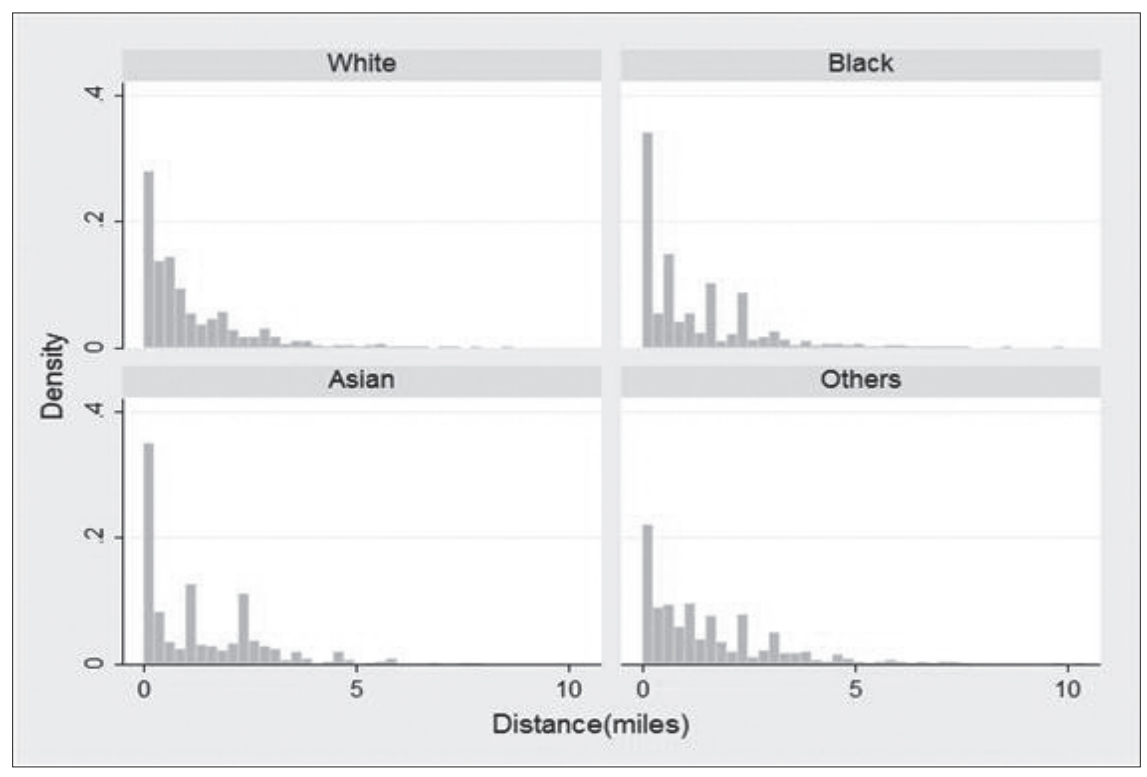

Figure 3. Insurance type: Private, Medicaid, Medicare, or uninsured

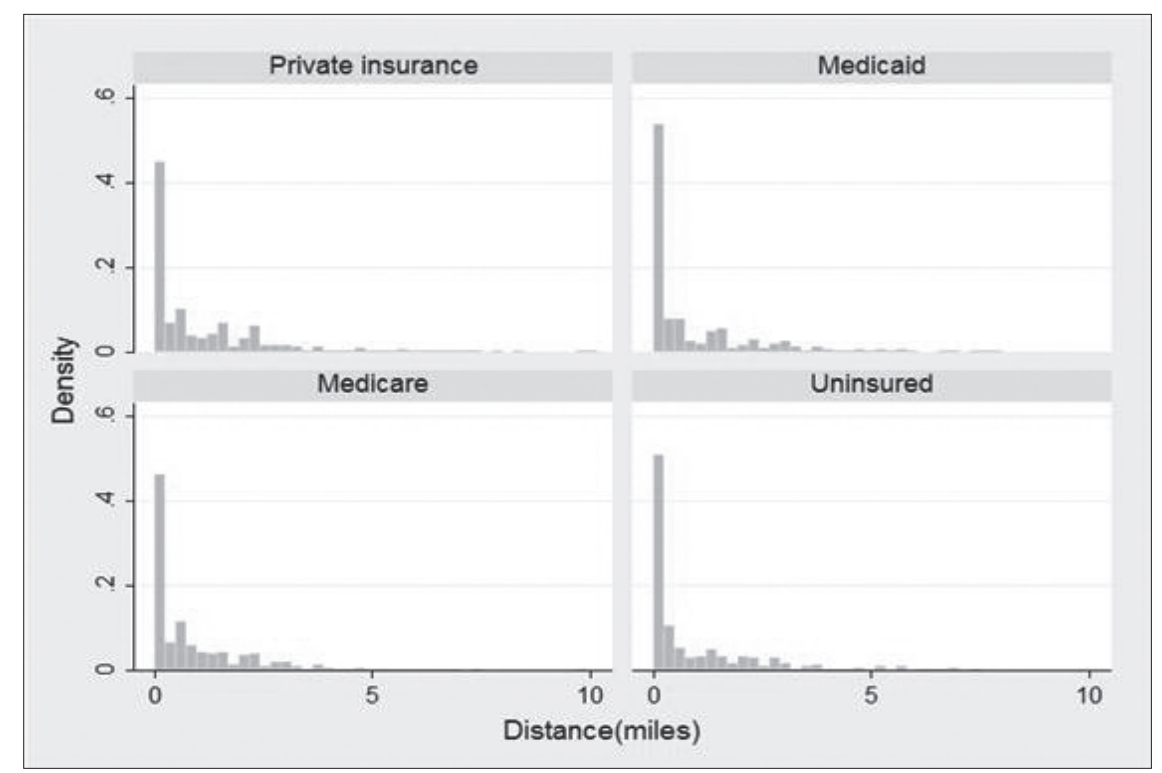


Second, we investigate how distance limits disadvantaged inpatients' in their choice of hospital by using two different models. During the period analyzed, in New York County, 20,929 inpatients could choose 1 of 15 hospitals (14 within the market and 1 outside the market). In our analyses, distance $(-0.667 * * *)$ in the second model is significantly and negatively associated with probability of hospital choice (odds ratio: 051). This indicates that hospital choice is associated with the geographic barriers inpatients confront in the city. The finding supports our hypoth-

Table 3. Factors Associated with Hospital Choices

\begin{tabular}{|c|c|c|c|c|c|c|}
\hline & \multicolumn{3}{|c|}{ Model 1} & \multicolumn{3}{|c|}{ Model 2} \\
\hline & $\begin{array}{l}\text { Odds } \\
\text { Ratio }\end{array}$ & Coefficient & $\begin{array}{l}\text { Standard } \\
\text { Error }\end{array}$ & $\begin{array}{l}\text { Odds } \\
\text { Ratio }\end{array}$ & Coefficient & $\begin{array}{l}\text { Standard } \\
\text { Error }\end{array}$ \\
\hline Distance (Miles) & & & & 0.51 & $-0.667^{\star * *}$ & 0.044 \\
\hline Distance Squared & & & & 1.06 & $0.058^{* * *}$ & 0.003 \\
\hline \multicolumn{7}{|l|}{$\begin{array}{l}\text { Demographic } \\
\text { Factors }\end{array}$} \\
\hline $\begin{array}{l}\text { D*Gender } \\
\text { (Reference Group } \\
=\text { Male) }\end{array}$ & 0.93 & $-0.070^{\star \star \star}$ & 0.017 & 0.95 & $-0.054^{\star \star \star}$ & 0.016 \\
\hline$D^{\star}$ Age & 0.99 & $-0.011^{* \star *}$ & 0.000 & 0.99 & $-0.005^{\star * *}$ & 0.001 \\
\hline \multicolumn{7}{|l|}{$\begin{array}{l}\text { Race (Reference } \\
\text { Group = White) }\end{array}$} \\
\hline D*Black & 0.88 & $-0.130^{* \star *}$ & 0.020 & 0.93 & $-0.073^{\star \star \star}$ & 0.021 \\
\hline D*Asian & 0.70 & $-0.352^{\star \star \star}$ & 0.042 & 0.72 & $-0.325^{\star \star \star}$ & 0.041 \\
\hline $\mathrm{D}^{\star}$ Other & 1.01 & 0.014 & 0.021 & 1.01 & 0.014 & 0.021 \\
\hline \multicolumn{7}{|l|}{$\begin{array}{l}\text { Insurance Type } \\
\text { (Reference Group } \\
\text { = Private) }\end{array}$} \\
\hline D*Uninsured & 1.02 & 0.017 & 0.042 & 1.09 & $0.091^{*}$ & 0.041 \\
\hline D*Medicaid & 0.93 & $-0.072^{*}$ & 0.029 & 1.01 & 0.010 & 0.029 \\
\hline$D^{\star}$ Medicare & 1.04 & 0.040 & 0.021 & 1.02 & 0.016 & 0.020 \\
\hline$D^{\star}$ Other & 1.06 & 0.058 & 0.033 & 1.12 & $0.112^{\star \star \star}$ & 0.033 \\
\hline $\begin{array}{l}D^{\star} \text { Total Length of } \\
\text { Stay }\end{array}$ & 1.00 & 0.001 & 0.001 & 1.00 & 0.002 & 0.001 \\
\hline$D *$ Surgical & 1.37 & $0.314^{\star * *}$ & 0.017 & 1.35 & $0.302^{\star \star \star}$ & 0.017 \\
\hline Log Likelihood & \multicolumn{3}{|c|}{$-29,404$} & \multicolumn{3}{|c|}{$-29,225$} \\
\hline Observations & \multicolumn{6}{|c|}{20,929} \\
\hline
\end{tabular}

Notes: 15 hospital-dummy variables $\left(\delta_{\mathrm{j}}\right)$ are omitted in the table. D stands for distance. ${ }^{* * *} p<0.001$, ${ }^{* *} p<0.01{ }^{*} p<0.05$. 
esis that individuals' risk of having to make a nonoptimal decision increases when the distance costs to choose a different provider go up.

More importantly, this finding indicates that the interaction terms between socioeconomic status and distances turn out to be significantly negative. For instance, female $\left(-0.070^{* * *}\right)$, older $\left(-0.011^{* * *}\right)$, black $\left(-0.130^{* * *}\right)$ or Asian $\left(-0.352^{* * *}\right)$ inpatients are less likely to choose a distant hospital than young, male, white inpatients, after distance and controls for other hospital characteristics have been taken into account. This implies that the geographic barriers that prevent inpatients from choosing more distant hospitals are associated with their low socioeconomic status; in choosing hospitals because they are nearby, then, they might not be getting the services that would be most appropriate for them. Furthermore, the results confirm that Medicaid inpatients are less likely to choose a more distant hospital than patients with private insurance. The finding supports our second hypothesis: that the risk of making a nonoptimal decision is much higher among inpatients of low socioeconomic status or who have public insurance than among other groups. The control variable, the severity of the medical condition, which is determined by whether the inpatient has a surgical diagnosis-related group code or not and by the length of the stay, is included because inpatients having serious medical are more likely to go to a nearby hospital.

\section{CONCLUSION}

Inpatients of low socioeconomic status or Medicaid inpatients find geography creates a barrier to obtaining a choice of hospitals and thus, potentially, better quality hospital care. This is due to two reasons. First, the greater the distance between the inpatient's residence and a hospital, the less likely are low socioeconomic status inpatients to choose that hospital. Second, by limiting themselves geographically, these inpatients reduce their ability to choose hospitals based on other factors. Inpatients of higher socioeconomic statuses seem less affected by geographic issues and so are more willing to patronize hospitals located further from their places of residence. Issues of economic inequality (as well as social and racial issues), therefore, could be illustrated by these findings. More interesting, we also observe that inpatients who have public insurance like Medicaid are less likely to have access to health care services than those who have private insurance.

Our results thus prove both our first and our second hypotheses. They indicate the importance that location and distance can play in preventing economically disadvantaged people from choosing the hospital best suited to their needs. These 
results could have important implications for the locating of future hospitals catering to urban residents of a low socioeconomic status. They could also have important implications for political debates regarding the allocation and distribution of government public health funds.

In addition, they also help rectify a deficit in the existing research literature. Previous research, as has been noted, only discusses geographic barriers in connection with smaller cities the treatment of a specific aliment, or nonhospital settings or does not concentrate on how geographic barriers relate to socioeconomic factors and interact with them. Given the large number of people who use hospitals in a large urban setting, this gap in the literature has left an important aspect of the issue of geographic access to health care unexamined. We believe our research helps fill this void, perhaps most importantly with regard to the question of how geographic barriers relate to socioeconomic factors and interact with them. Thus, we feel researchers, policy makers, and administrators will be able to utilize the results of our research to find ways to reduce disparities in access to health care.

A limitation of this study and an area of further research would be the influence of other locational factors besides residence on individuals' choice of hospitals. An inpatient's work location may, for instance, have a strong influence on the inpatient's choice of hospital, particularly if the inpatient's physician is located in close proximity to the work location. Similarly, the location of an inpatient's relatives may also have a strong influence on the inpatient's choice of hospital, since the inpatient may need assistance traveling to or from the hospital or may want family visits if they are hospitalized for multiple days.

We also do not consider the characteristics of the various hospitals and the possibility of a disparity in the quality of care received by the inpatients at the hospitals they used. Yet previous studies (Roh et al., 2008; Roh \& Moon, 2016) find that inpatients seem to respond positively to certain hospital characteristics and such as a greater array of services, higher market share, a greater number of beds, and governance by a corporation. They seem to influence hospital choice; separately, Luft et al. (1990) discuss the importance of whether a hospital is a teaching hospital (in our study, these potential factors were controlled for in the form of dummy variables for each hospital in the analysis). Furthermore, Gray, Lin, Cooperberg, Jemal, and Efstathiou (2016) have noted that socioeconomic status can have an effect on the treatment of prostate cancer, and similar results in connection with other medical conditions have been discussed by O'Brien-Irr et al. (2012) and Giacovelli et al. (2008). Our research focuses only on the effect of socioeconomic status on a inpatient's choice of hospital, not on either the treatment or the quality of care received once there or on the overall characteristics of the hospitals involved (although we 
controlled for these factors) (Lee, 2018; Lee \& Park, 2018). However, hospital characteristics and quality of care versus socioeconomic status in New York City may be germane to a number of public health issues likely to affect the city in the future. Further research in this area may, therefore, prove beneficial to the city public health and social policies.

\section{REFERENCES}

Ahern, J., Galea, S., Hubbard, A., \& Karpati, A. 2008. Population vulnerabilities and capacities related to health: A test of a model. Social Science and Medicine, 66(3): 691-703.

Akinyemiju, T., Sakhuja, S., \& Vin Raviv, N. 2016. Racial and socio-economic disparities in breast cancer hospitalization outcomes by insurance status. Cancer Epidemiology, 43: 63-69.

Amit, R., \& Schoemaker, P. J. H. 1993. Strategic assets and organizational rent. Strategic Management Journal, 14(1): 33-46.

Berry, S., Levinsohn, J., \& Pakes, A. 2004. Differentiated products demand systems from a combination of micro and macro data: The new car market. Journal of Political Economy, 112(1); 68-105.

Borah, B. 2006. A mixed logit model of health care provider choice: Analysis of NSS data for rural India. Health Economics, 15: 915-932.

Bow, C. J. D., Waters, N. M., Faris, P. D., Seidel, J. E., Galbraith, P. D., Knudtson, M. L., Ghali, W. A., \& the APPROACH Investigators. 2004. Accuracy of city postal code coordinates as a proxy for location of residence. International Journal of Health Geographics, 3(1): 5.

Brau, R., Moro, D., \& Balia, S. 2016. Modelling the individual choice of distant hospital care. Retrieved on December 22, 2018, www.siecon.org/online/wp-content/uploads/2016/09/MORO-1.pdf.

Bronstein, J. M., \& Morrisey, M. A. 1991. Bypassing rural hospitals for obstetrics care. Journal of Health Politics, Policy and Law, 16(1): 87-118.

Brown, E. R., Davidson, P. L., Yu, H., Wyn, R., Andersen, R. M., Becerra, L., \& Razack, N. 2004. Effects of community factors on access to ambulatory care for lower-income adults in large urban communities. Inquiry, 41(1): 39-56.

Canaviri, J. A. 2007. A Random parameter logit model for modeling health care provider choice in Bolivia. Munich Personal RePEc Archive. Retrieved on December 22, 2018, http://mpra.ub.uni-muenchen.de/3263. 
Celikel, A., Hustache, J-C., De Lepinay, I., Martin, K., \& Melrose, A. 2005. Environmental tradeoffs assessment around airports. In Proceedings of the sixth USA/ Europe ATM seminar. http://atmseminar.org/seminarContent/seminar6/papers/ p_053_EIM.pdf.

Dor, A., Gertler, P., \& Van Der Gaag, J. 1987. Non-price rationing and the choice of medical care providers in rural Cote D'Ivoire. Journal of Health Economics, 6(4): 291-304.

Fong, Z. V., Bababekov, Y. J., Fernandez-del Castillo, C. F., Ferrone, C. R., Warshaw, A. L., Lillemoe, K. D., \& Chang, D. C. 2016. Are patients making optimal choices when selecting hospitals? Journal of the American College of Surgeons, 223(4): 106-107.

Gesler, W. M., \& Meade, M. S. 1988. Locational and population factors in health care-seeking behavior in Savannah, Georgia. Health Services Research, 23(3): 443-462.

Giacovelli, J. K., Egorova, N., Nowygrod, R., Gelijns, A., Kent, K. C., \& Morrissey, N. J. 2008. Insurance status predicts access to care and outcomes of vascular disease. Journal of Vascular Surgery, 48(4): 905-911.

Gössling, T. 2003. The price of morality: An analysis of personality, moral behaviour, and social rules in economic terms. Journal of Business Ethics, 45(1): 121-131.

Gray, P. J., Lin, C. C., Cooperberg, M. J., Jemal, A., \& Efstathiou, J. A. 2016. Temporal trends and the impact of race, insurance, and socioeconomic status in the management of localized prostate cancer. European Urology, 71(5): 729-737.

Grubesic, T. H., \& Matisziw, T. C. 2006. On the use of ZIP codes and ZIP code tabulation areas (ZCTAs) for the spatial analysis of epidemiological data. International Journal of Health Geographics, 5(58): 1-15.

Guagliardo, M. F. 2004. Spatial accessibility of primary care: concepts, methods and challenges. International Journal of Health Geographics, 3(3): 1-13.

Guagliardo, M. F., Ronzio, C. R., Cheung, I., Chacko, E., \& Joseph, J. G. 2004. Physician accessibility: An urban case study of pediatric providers. Health and Place, 10(3): 273-283.

Gusmano, M. K., Burke, C., \& Thompson, F. J. 2012. Health care politics and policy in New York State. In G. Benjamin (ed.), The Oxford handbook of New York State government and politics (pp.1-44). Oxford University Press, New York.

Hall, M., \& Owings, M. F. 2015. Changing patterns in hospitalization and inpatient surgery of rural and urban residents. Presentation, 2015 National Conference on Health Statistics. Retrieved on December 22, 2018, www.cdc.gov/nchs/ppt/ nchs2015/Hall_Tuesday_Salon_D_BB1.pdf.

Haynes, R., Lovett, A., \& Sünnenberg, G. 2003. Potential accessibility, travel time, 
and consumer choice: Geographical variations in general medical practice registrations in eastern England. Environment and Planning A, 35(1): 1733-1750.

He, X. 2011. Factors affecting rural Kentucky patients' hospital choice and bypass behavior. Master's thesis, University of Kentucky http://uknowledge.uky.edu/ gradschool_theses/115.

Jacobs, B., Ir, P., Bigdeli, M., Annear, P. L., \& van Damme, W. 2011. Addressing access barriers to health services: An analytical framework for selecting appropriate interventions in low-income Asian countries. Health Policy and Planning, 27(4): 288-300.

Keating, N. L., Kouri, E. M., He, Y., Freedman, R. A., Volya, R., \& Zaslavsky, A. M. 2016. Location isn't everything: Proximity, hospital characteristics, choice of hospital, and disparities for breast cancer surgery patients. Health Services Research, 51(4): 1561-1583.

Krieger, N., Chen, J. T., Waterman, P. D., Rehkopf, D. H., Subramanian, S. V. 2005. Painting a truer picture of US socioeconomic and racial/ethnic health inequalities: The Public Health Disparities Geocoding Project. American Journal of Public Health, 95(2): 312-323.

Lee, J. B, \& Park, S. 2018. A study of consumer choices in public and nonprofit organizations: The case of New York County health service markets. Korean Journal of Public Administration, 56(2): 33-54.

Lee, J. B. 2018. What drives for-profit and nonprofit organizations' entry into voucher markets? International Journal of Public Administration. https://doi.org/10.108 $0 / 01900692.2018 .1517783$.

Liu, C.-M. 2016. The relationship between the adoption of patient centered Medical home and the quality of medication use: Results from the National Ambulatory Medical Care Survey. PhD diss., University of Michigan.

Liu, J., Bellamy, G., Barnet, B., \& Weng, S. 2008. Bypass of local primary care in rural counties: Effect of patient and community characteristics. Annals of Family Medicine, 6(2): 124-130.

Lu, M., Dong, Z. Y., \& Saha, T. K. 2005. A framework for transmission planning in a competitive electricity market. In 2005 Transmission and Distribution Conference and Exhibition: Asia and Pacific (pp. 1-6). Piscataway, NJ: IEEE/PES.

Luft, H.S., Garnick, D.W., Mark, D.H., Peltzman, D. J., Phibbs, C. S., Lichtenberg, E., \& McPhee, S.J. 1990. Does quality influence choice of hospital? Journal of the American Medical Association, 263(21): 2899-2906.

Luo, W., \& Wang, F. 2003. Measures of spatial accessibility to health care in a GIS environment: Synthesis and a case study in the Chicago region. Environment and Planning B: Planning and Design, 30(6): 865-884. 
McFadden, D. 1974. The measurement of urban travel demand. Journal of Public Economics, 3(4): 303-328.

McLafferty, S., \& Grady, S. 2005. Immigration and geographic access to prenatal clinics in Brooklyn, NY: A geographic information systems analysis. American Journal of Public Health, 95(4): 638-40.

Morrill, R. L., Earickson, R. J., \& Rees, P. 1970. Factors influencing distances traveled to hospitals. Economic Geography, 46(2): 161-171.

Moscone, F., Tosetti, E., \& Vittadini, G. 2012. Social interaction in patients' hospital choice: Evidence from Italy. Journal of the Royal Statistical Society: Series A (Statistics in Society), 175(2): 453-472.

New York City Department of Health and Mental Hygiene. 2007. Health care access among adults in New York City: The importance of having insurance and a regular care provider. Retrieved on December 22, 2018, https://www1.nyc.gov/ assets/doh/downloads/pdf/hca/hca-nyc-adults.pdf.

New York City Department of Health and Mental Hygiene. 2010. Community health assessment: 2010-2013, 29: 48-57.

New York City Department of Health and Mental Hygiene. 2014. Uninsured adults in New York City. Epi Data Brief 43.

Nguyen, Q. C., Waddell, E. N., Thomas, J. C., Huston, S. L., Kerker, B. D., \& Gwynn, R. C. 2011. Awareness, treatment, and control of hypertension and hypercholesterolemia among insured residents of New York City, 2004. Preventing chronic disease: Public Health Research, Practice, and Policy, 8(5): 1-7.

O’Brien-Irr, M. S., Harris, L. M., Dosluoglu, H. H., \& Dryjski, M. L. 2012. Procedural trends in the treatment of peripheral arterial disease by insurer status in New York State. Journal of the American College of Surgeons, 215(3): 311-321.

Ona, L., Allen, J. E., Davis, A. F., \& He, X. 2016. Determinants of bypass behavior for critical access hospitals in rural Kentucky. Community and economic development initiative of Kentucky. http://cedik.ca.uky.edu/files/aec_staff_paper_496_determinants_of_bypass_behavior_for_cahs_in_rural_ky.pdf.

Park, C. 2011. Relationships between the growth of ethnic groups and socioeconomic conditions in U.S. metropolitan areas. Korean Journal of Policy Studies, 26(2): 121-136.

Peipins, L. A., Graham, S., Young, R., Lewis, B., Foster, S., Flanagan, B., \& Dent, A. 2011. Time and distance barriers to mammography facilities in the Atlanta metropolitan area. Journal of Community Health, 36(4): 675-683.

Pope, D. G. 2009. Reacting to rankings: Evidence from America's best hospitals. Journal of Health Economics, 28(6): 1154-1165.

Radcliff, T. A., Brasure, M., Moscovice, I. S., \& Stensland, J. T. 2003. Understanding 
rural hospital bypass behavior. Journal of Rural Health, 19(3): 252-259.

Raufman, J., Farley, S. M., Olson, C., \& Kerker, B. 2007. Access to health care and health insurance: New York City community health survey. New York City Department of Health and Mental Hygiene.

Rocha, C. J., \& Kabalka, L. E. 1999. A comparison study of access to health care under a Medicaid managed care program. Health and Social Work, 24(3): 169180.

Roh, C.-Y., \& Lee, K. H. 2005. Hospital choice by rural Medicare beneficiaries: Does hospital ownership matter? A Colorado case. Journal of Health and Human Services Administration, 28(3): 346-365.

Roh, C.-Y., Lee, K. H., \& Fottler, M. D. 2008. Determinants of hospital choice of rural hospital patients: The impact of networks, service scopes, and market competition. Journal of Medical Systems, 32(4): 343-353.

Roh, C., and Moon, M. J. 2016. Does governance affect organizational performance? Governance structure and hospital performance in Tennessee. Korean Journal of Policy Studies, 31(2): 23-40,.

Tai, W., Porell, F. W., Adams, E. K. 2004. Hospital choice of rural Medicare beneficiaries: Patient, hospital attributes, and the patient-physician relationship. Health Services Research, 39(6): 1903-1922.

U.S. Census Bureau. 2015. U.S. cities are home to 62.7 percent of the U.S. population, but comprise just 3.5 percent of land area. Press release CB15-33. Retrieved on December 22, 2018, www.census.gov/newsroom/press-releases/2015/cb15-33. html.

Varkevisser, M., and van der Geest, S. A. 2007. Why do patients bypass the nearest hospital? An empirical analysis for orthopaedic care and neurosurgery in the Netherlands. The European Journal of Health Economics, 8(3): 287-295.

Ward, R. B. 2006. Health and Mental Hygiene. In R. Ward (ed.), New York State government (pp. 301-333). Albany, NY: Rockefeller Institute Press.

Yang, D., Goerge, R., \& Mullner, R. 2006. Comparing GIS-based methods of measuring spatial accessibility to health services. Journal of Medical Systems, 30(1): 23-32. 
